\title{
Do oil prices and exchange rates affect the US stock market? New evidence from the asymmetric cointegration approach.
}

\author{
Rafailidis Panagiotis $^{1}$ and Katrakilidis Constantinos ${ }^{1}$
}

\begin{abstract}
In this paper, we study the dynamics between US stock prices, exchange rates and oil prices. The data used are quarterly, covers the period from 1986 to 2016 and includes the Standard \& Poor's 500 spot prices, the West Texas Intermediate spot prices and the effective exchange rate of US Dollar. We examine the presence of different sources of nonlinearities. The empirical analysis is based on the asymmetric ARDL cointegration methodology proposed by Shin et al (2011). The evidence implies that ignoring possible non-linearities lead to misleading results. The analysis reveals new evidence such as the existence of several structural brakes and asymmetries in both long-run and short-run relationships among the examined variables and that could be of major importance for researchers and other market participants.
\end{abstract}

JEL classification numbers: F3, G1

Keywords: stock prices; exchange rates; oil prices; asymmetric cointegration; ARDL; NARDL; Forecasting

\section{Introduction}

Understanding the dynamics of stock markets, exchange rates, and commodity prices is an issue of ongoing research in financial market literature for researchers, investors, and policymakers. Oil is an important input in production and affects productivity, stock prices, and exchange rates through several channels. Stock market represents real economy and, therefore, reflects the impacts of exchange rates and oil prices. From the perspective of efficient market theory and asset pricing models, stock prices are depending on the fundamentals that describe the performance of the economy (Merton. 1973; Ross, 1976; Cox et al, 1985). Exchange rates affect stock prices through countries' competitiveness. Exchange rates fluctuations affect input and output prices (Joseph, 2002). These models are known as flow oriented (Dornbusch \& Fisher, 1980). As the value of a firm is estimated by the future cash flows, the effect of prices is transmitted to the value of the firm and thus to its share prices. Movements in the stock market may also affect exchange rates. Furthermore, as the theory of the uncovered interest rate parity imply the expected values of the exchange rates affect both domestic and foreign interest rates. According to the theory, another approach known as "stock-oriented" models, [Branson, 1980; Frankel, 1983] implies that exchange rates determine the supply and demand for assets such as stocks and bonds. Since the values of financial assets are determined by the present values of their future cash flows [Huang et al, 1996], expectations of exchange rates play a key role in their value.

Portfolio balance models provide an alternative interpretation of the relationship between exchange rates

${ }^{1}$ Department of Economics, Aristotle University of Thessaloniki, Greece

Article Info: Received: July 1, 2021. Revised: September 1, 2021. Published online: September 12, 2021. 
and stock prices, stressing the role of capital account transactions. Blooming stock market would attract capital flows from foreign investors, which will increase the demand for its currency. The reverse would happen in the case of falling stock prices where the investors would try to sell their stocks to avoid further losses and would convert their money into foreign currency to move out of the country. Such a scenario would lead to local currency depreciation. As a result, rising (declining) stock prices would lead to an appreciation (depreciation) in exchange rates. In other words, movements in stock prices may affect exchange rates and money demand because investors' wealth and liquidity demand could be a function of the performance of the stock market [Mishra, 2004]. Therefore, stock prices may both affect and be affected by exchange rate dynamics.

Oil is also an important determinant of both stock prices and exchange rates. Oil prices can affect stock prices directly by impacting future cash flows or through the interest rate used to discount the future cash flows. Oil prices and exchange rates linkages can be explained through the terms of either trade or wealth effect. According to the first transmission channel in an oil-importing country, higher oil prices lead to a deterioration of the trade balance. Increased prices and weakening competitiveness shrink the disposable income and also the value of the firm, lowering, as a result, the value of the local currency. Based on the wealth effect [Krugman, 1983; Golub, 1983] higher oil prices will transfer wealth from oil importers to oil exporters, which in turn changes the exchange rate of the importing country through current account imbalances and portfolio reallocation. Also, according to the theory, an increase in oil prices for an oil exporting country may cause an appreciation of the real exchange rate, reduce its competitiveness in the non-oil exporting sector, and limit its ability to diversify its exports; this phenomenon is called "Dutch disease". Exchange rates can affect oil prices through their effects on oil supply and oil demand as well as on financial markets. A depreciation of the US dollar will push oil exporting countries to increase oil prices in order to stabilize their revenues thus they may decrease supply. However, from the perspective of demand, a depreciation of the US dollar may increase oil demand as oil relative prices decrease for other countries.

The present research, contributes to the understanding of the linkages between US stock prices, exchange rates and oil prices, also examining for the presence of asymmetric long-run effects and thus its results could be useful to investors and other market participants, such as financial managers, analysts and firms and policy makers.

\section{Literature Review}

The literature concerning oil prices and exchange rates as well as empirical evidence supports the theory that the effects run either from oil to exchange rate or in the other direction. Also, the links may be either negative or positive. Hence the results concerning both the sign and direction of the causality are controversial. Bénassy-Quéré et al (2007), using a VECM model found that a rise in the oil price coincides with an appreciation of the dollar in the long run. Coudert et al (2008), using cointegration analysis found that a negative long-run relationship exists with causality running from oil to exchange rates. Chen \& Chen (2007), using panel analysis for the G7 countries found that oil price is the dominant source of real exchange rate movements and that increasing oil prices would lead to an appreciation of the U.S. dollar. Lizardo \& Mollick (2010) provided evidence that an increase in real oil prices leads to a significant depreciation of the USD against the currencies of net oil exporting countries, such as Canada, Mexico, and Russia. On the other hand, they found that the currencies of oil importers, such as Japan and Denmark, suffer a depreciation relative to the US Dollar.

Zhang et al (2008) using a VECM model found that there is a positive long-term equilibrium cointegrating relationship between the oil price and US dollar exchange rate. By applying the Granger causality test they found that the US dollar does Granger cause oil prices. Krichene (2005) supports the existence of a relationship between exchange rates and oil prices with the causality running from exchange rates to oil 
prices. Exchange rates have a significant impact on oil prices since a depreciation of the US Dollar could lead to an increase in oil prices. There are very few studies that support the existence of bidirectional causality [Chen et al, 2010; Groen \& Pesenti, 2011].

Concerning the relationship between oil prices and stock prices in oil importing countries, most researches provide only short-term evidence of negative impacts of oil-price changes to stock returns [Sadorsky, 1999; Park \& Ratti, 2008]. Other studies suggest that oil price changes do not determine asset prices or that the relationship between them is positive [Kilian \& Park, 2009; Apergis \& Miller, 2009; Narayan \& Narayan, 2010].

\subsection{Stock price changes and exchange rates}

The interest in the examination of the correlation between the exchange market and the stock market has been increased in the last decades by the creation of the new capital markets, the relaxation of foreign capital controls as well as the opportunity of new and more flexible exchange rate regimes. The more flexible exchange rate regimes adopted by many countries in the $80 \mathrm{~s}$ and $90 \mathrm{~s}$ are also responsible for the instability of foreign exchange markets and the higher risk in the investments in this field [Phylaktis \& Ravazzolo, 2005].

It is a classical assumption nowadays that there is a relationship between the stock market and the exchange rates. Some exchange rate determination models, such as the flow-oriented models, imply that the currency movement can influence the international competitions and the balance of trade and the real output of the country that will influence the cash flow and the stock markets [Dornbusch \& Fisher, 1980]. Vice versa, the movement in the stock market can influence the exchange rates. For example, according to monetarist models of exchange rate determination [Gavin, 1989] and to portfolio balance models [Branson, 1983; Frankel, 1983], it is mentioned that equities can influence the pattern of exchange rates.

There are many previous studies that investigated the linkage between stock market and exchange market; these studies presented mixed results regarding this linkage. Aggarwal (1981) concluded that the revaluation of the US dollar has a positive relationship with the stock market returns. Kollias et al (2012), through rolling cointegration analysis indicate no long run, but causal relationship between euro-dollar rate and two European stock indices, which is partially confirmed by Kollias et al (2016). On the other hand, Soenen \& Hennigar (1988) found a significantly negative relationship between the two variables but this could also be attributed to the fact that the researchers studied data from a different period (19801986) than Aggarwal (1981) did. Roll (1992) stressed the existence of a positive relationship by utilizing daily data for the years 1988- 1991 while Chow et al (1997) who analyzed monthly data did not manage to present a relationship.

As Phylaktis \& Ravazzolo (2005) state, a cointegration approach can be beneficial because it solves the problem of non- stationarity while, at the same time, gives the chance for the examination of the linkage between stock markets and exchange rated in terms of levels and differences. They also imply that a causal relationship between the stock markets and the foreign exchange markets exists, as they state that incapability of tracing the causal relationship between stock market and foreign exchange market can happen because of the omission of a valuable variable in the analysis.

\subsection{Stock price changes and oil price changes}

From what is known so far, oil prices uncertainty can affect various fields of economy, such as production, investment or consumption. This occurs due to the commodity and financial property of oil. Since the oil price can determine or change crucial financial decisions it does not come as a surprise that it influences the asset returns as well [Xiao et al, 2018]. The relationship of the oil market and the stock market has been studied at least for the last two decades with many researchers contributing with valuable data [Jones \& Kaul, 1996; Basher \& Sadorsky, 2006; Kilian \& Park, 2009]. 
Most of the research has focused on the interaction between oil price and the stock market in the developed countries. Nevertheless, it is not shown that the interaction follows the same pattern in developing countries as well. The studies examining the correlation in developing countries have offered mixed results. Some researchers have concluded that the oil price changes can have a detrimental impact on the stock market [Jones \& Kaul, 1996; Basher \& Sadorsky, 2006; Lee \& Zeng, 2011] while others find a positive relationship [Kilian \& Park, 2009; Narayan \& Narayan, 2010; Arouri \& Rault, 2010] or even a non-significant impact of oil price changes on the stock market [Apergis \& Miller, 2009; Mohanty et al, 2010]. These controvercial results are intensified due to the presence of exogenous factors that may affect the relationship of the two markets, such as geopolitical risks (Antonakakis et al, 2017), terrorism actions and war conflicts (Kollias et al, 2013). The research outcomes can be seriously determined by the implementation of different research techniques [Narayan \& Sharma, 2011; Moya-Martínez et al, 2014], but even in this case, it was shown that the oil and stock market are linked but in different ways, according to the sector.

Moreover, some studies also fail to recognize or to take into consideration the asymmetric effects of the oil price on the stock market. The heterogeneous results and the lack of evidence regarding the asymmetric effect shown that this correlation is a complicated one [Ghosh \& Kanjilal, 2016; Salisu \& Isah, 2017] and that needs to be further studied. The asymmetric nature of oil price change can be understood in many ways. First of all, the cash flow of companies that use the oil can be influenced by the positive or negative change in the oil market, causing the asymmetric relationship between oil market and stock market [Salisu \& Isah, 2017]. Apart from that, investors may react heterogeneously to the positive or negative atmosphere of the oil market and their reaction can lead to asymmetric effects of oil to the stock market. When studies use an asymmetric or nonlinear analysis to test the correlation of the two variables the results show that indeed there are asymmetric or nonlinear patterns of connection between them [Xiao et al, 2018]. Therefore, an examination of the asymmetric relationship between the variables can facilitate the investors to design better strategies during periods of oil market uncertainty.

Alsalman \& Herrera (2015) have presented the asymmetric impact of oil price on stock return in specific sectors, even when these sectors are not very energy-demanding or energy-producing. Additionally, Narayan \& Gupta (2015) concluded that unfavorable oil price changes can be an accurate predictor of stock returns in the USA; in particular, they can predict the stock returns better than a positive oil price change can do.

\subsection{Stock price changes, exchange rates and oil price changes}

In the recent literature stock market, oil price and exchange rates have studied by very few researchers together. Nevertheless these financial factors lead to different results due to the difference in the methodology of each study. For example, Basher et al (2012) used VAR methodology and some other additional factors while Jain \& Biswal (2016) examined the linkage between these three factors but they also add gold as a forth variable.

Researchers have found significant interrelations between oil price, stock market and currency Roubaud \& Arouri (2018). In a recently published study, Bai \& Koong (2018) present the relationships between oil prices, exchange rates and stock market in the US and China between 1991 and 2015 identifying the difference in these relationships across time. It is also stressed that appreciation of currency positively influences the stock market index and that higher oil price causes currency appreciation Delgado et al (2018).

\section{Methodology and data}

The period of analysis runs from 1986 to 2016. The data are in Quarterly frequency. The variables used are: The Standard \& Poor's500 spot prices as the US market share price (RMSP), that is a stock market 
index based on the market capitalizations of 500 large companies that is considered as a benchmark of the U.S. stock market. For oil prices we used the West Texas Intermediate (RWTI) spot prices, which are a grade of crude oil and the real effective exchange rate of US Dollar. The real effective exchange rate (REER) is a weighted average of a country's currency relative to an index or basket of other major currencies. The weights are based on the relative trade balance of a country's currency against its major trading partners. The consumer price index (CPI) has been used in order to express the real prices of all variables. The sources used are the Bloomberg and the US energy information administrator EIA. It is very useful to take into consideration the evolution of the examined series. In order to do so, we present the following graph with the historical prices:

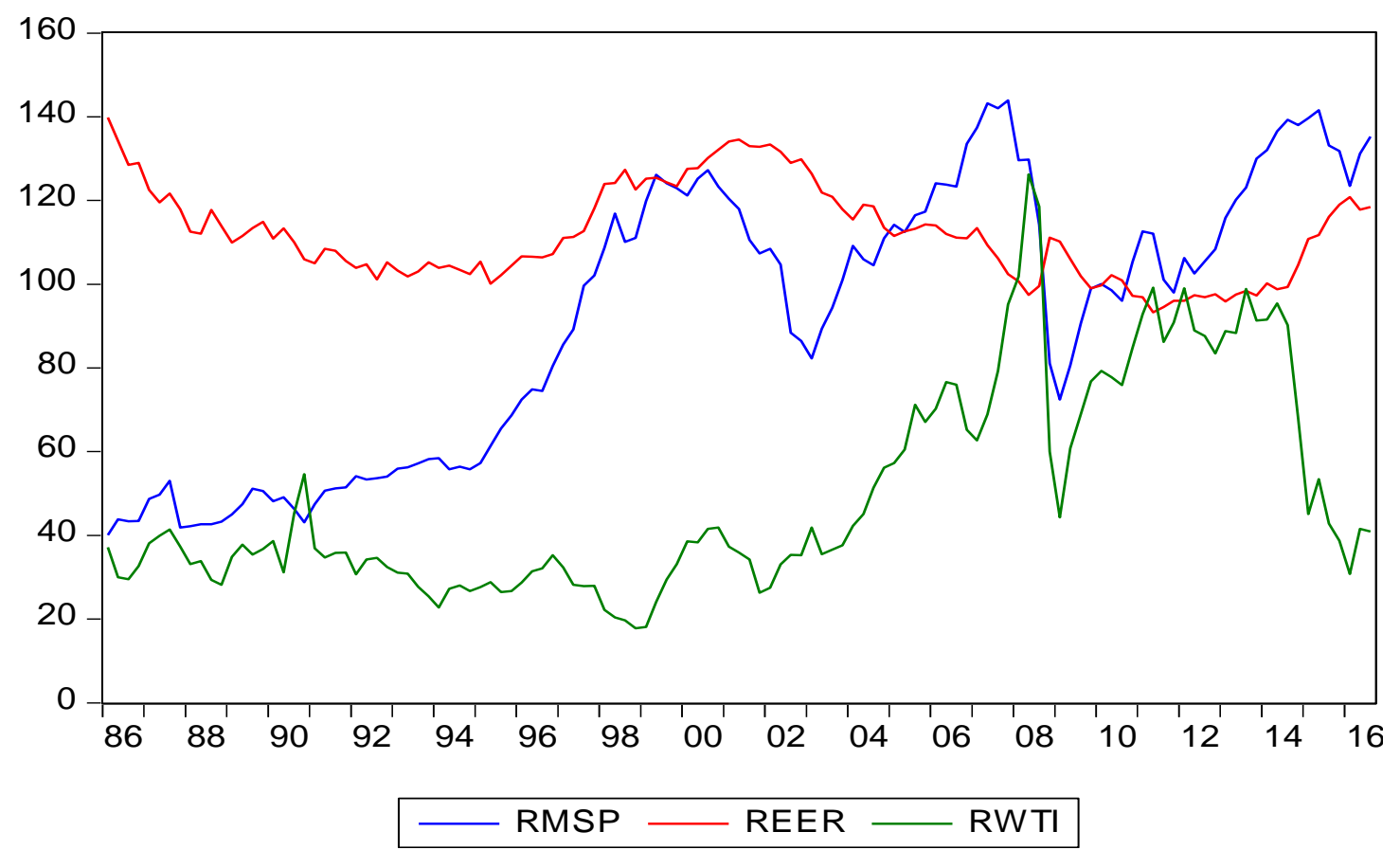

Figure.1: Historical prices of the examined variables

In the first step we test for the integration properties of the variables that are necessary when applying the cointegration framework. We use the Augmented Dickey-Fuller (1979) unit root test (ADF), the PhillipsPerron unit root test (PP) Phillips \& Perron (1988) and the Kwiatkowski-Phillips-Schmidt-Shin stationarity test (KPSS) (Kwiatkowski et al (1992). In the next step, after we investigate the integration properties of the series, we proceed with testing for cointegration. Cointegration refers to the existence of possible comovements among certain variables in the long-run. In this context, if two variables are found cointegrated, means that, although they may drift apart from each other, in the long-run they tend to return to equilibrium.

We employ the ARDL [Pesaran \& Shin, 1999; Pesaran et al, 2001] approach which has the following form:

$\Phi(L) y_{t}=\alpha_{0}+\alpha_{1} w_{t}+\beta^{\prime}(L) x_{i t}+u_{t}$

where: $\Phi(L)=1-\sum_{i=1}^{\infty} \Phi_{i} L^{i} \quad$ and $\beta(L)=\sum_{j=1}^{\infty} \beta_{j} L^{j} \quad$, with $L$ being the lag operator and $w_{t}$ being a 
vector of deterministic variables such as the intercept, seasonal dummies, time trends or other exogenous variables. The existence of the long -run relation between the variables under investigation is tested by computing the Bound F-statistic based on a modified $F$ statistic on the lagged level terms of equation (1) in order to establish a long run relationship among the variables. The acceptance of the null hypothesis of no cointegration implies that the coefficients of the lagged level variables are jointly equal to zero. The orders of the lags in the ARDL model are selected using the Akaike Information (AIC) Criterion. In the next step we employ the nonlinear ARDL model, which is an expansion of the above linear ARDL model.The nonlinear ARDL cointegration methodology (NARDL) was developed by [1] and is a relatively new technique for detecting non-linearities focusing on asymmetries in both the long-and and short-run periods among cointegrated variables. Following [Bai \& Perron, 1998; Pesaran \& Shin, 1999; Pesaran et al, 2001] and [1], we consider the following nonlinear asymmetric cointegrating regression:

$$
y_{t}=\beta^{+} x_{t}^{+}+\beta^{-} x_{t}^{-}+u_{t}
$$

where $\beta^{+}$and $\beta^{-}$are the associated long-run parameters and $x_{t}$ is a $\mathrm{k} \times 1$ vector of regressors decomposed as:

$x_{t}=x_{0}+x_{t}^{+}+x_{t}^{-}$,

where, $x_{t}^{+}$and $x_{t}^{-}$are partial sum processes of positive and negative changes in $x_{t}$ :

$$
x_{t}^{+}=\sum_{i=1}^{t} \Delta x_{i}^{+}=\sum_{i=1}^{t} \max \left(\Delta x_{i}, 0\right) \text { and } x_{t}^{-}=\sum_{i=1}^{t} \Delta x_{i}^{-}=\sum_{i=1}^{t} \min \left(\Delta x_{i}, 0\right),
$$

By associating (2) to the $\operatorname{ARDL}(\mathrm{p}, \mathrm{q})$ case, we obtain the following asymmetric error correction model (AECM):

$$
\Delta y_{t}=\rho y_{t-1}+\theta^{+} x_{i-1}^{+}+\theta^{-} x_{i-1}^{-}+\sum_{i=1}^{p-1} \varphi_{i} \Delta y_{t-i}+\sum_{i=0}^{q}\left(\pi_{i}^{+} \Delta x_{t-i}^{+}+\pi_{i}^{-} \Delta x_{t-i}^{-}\right)+e_{t},
$$

where $\theta^{+}=-\rho \beta^{+}, \theta^{-}=-\rho \beta^{-}, \quad \pi_{0}^{+}=\beta^{+}+\omega, \quad \pi_{i}^{+}=-\beta^{+} \varphi_{i}+\psi_{2 i}, \quad \pi_{0}^{-}=\beta^{-}+\omega, \quad \pi_{i}^{-}=-\beta^{+} \varphi_{i}+\psi_{2 i}$ for $i=1, \ldots, p$.

This methodology follows four steps; namely, step one concerns the estimation of the regressors $x_{t}$ which are decomposed into $x_{t}^{+}$and $x_{t}^{-}$as it is described in equation 3; and it can be estimated by standard OLS. Step two is the establishment of the long-run relationship between the levels of the variables $y_{t}, x_{t}^{+}$, $x_{t}^{-}$, by means of a modified F-test, while using the bounds-testing procedure advanced by [53] and [1], which refers to the joint null, $\rho=\theta^{+}=\theta^{-}=0$ in equation 5. In step three, using the Wald test, we examine for long-run symmetry where, $\theta=\theta^{+}=\theta^{-}$, and short-run symmetry which can take one of the following forms (i) $\pi_{i}^{+}=\pi_{i}^{-}$for all $i=1, \ldots, q$ or (ii) $\sum_{i}^{q} \pi_{i}^{+}=\sum_{i}^{q} \pi_{i}^{-}$. In the forth step, we derive the asymmetric cumulative dynamic multiplier effects of a $m_{h}^{+}=\sum_{i=0}^{h} \frac{\partial y_{t+i}}{\partial x_{t}^{+}}, m_{h}^{-}=\sum_{i=0}^{h} \frac{\partial y_{t+i}}{\partial x_{t}^{-}}, h=0,1,2 \ldots$ 
Note that as $h \rightarrow \infty$, then $m_{h}^{+} \rightarrow \beta^{+}$and $m_{h}^{-} \rightarrow \beta^{-}$, where $\beta^{+}$and $\beta^{-}$are the asymmetric long-run coefficients calculated as below :

$\beta^{+}=-\theta^{+} / \rho$ and $\beta^{-}=-\theta^{-} / \rho$ respectively.

Moreover, in order to avoid possible sources of nonlinearities, such as the presence of structural breaks, which can lead to falsely results, Bai and Perron [1998; 2003] test for the detection of multiple breaks is implemented. The test is employed to the nonlinear asymmetric cointegrating regression as presented in equation 2, additional to the employed methodology, so that to count for both breaks and asymmetries.

\section{Empirical results}

The results of the Augmented Dickey-Fuller (1979) unit root test (ADF), the Phillips-Perron (1988) unit root test (PP) and the Kwiatkowski-Phillips-Schmidt-Shin (1992) stationarity test (KPSS) are presented in Table 1.

Table 1: Unit root and stationarity tests

\begin{tabular}{|c|c|c|c|}
\hline \multicolumn{4}{|c|}{ Levels } \\
\hline & $\mathrm{ADF}$ & PP & KPSS \\
\hline LMSP & -2.186 & -1.722 & $0.250 *$ \\
\hline REER & -1.884 & -2.058 & $0.133 * *$ \\
\hline LWTI & -2.073 & -2.267 & $0.164 * *$ \\
\hline \multicolumn{4}{|c|}{ First differences } \\
\hline & $\mathrm{ADF}$ & PP & KPSS \\
\hline LMSP & $-8.227 *$ & $-8.037 *$ & 0.039 \\
\hline REER & $-9.712 *$ & $-9.670 *$ & $0.159 * *$ \\
\hline LWTI & $-8.843 *$ & $-9.488 *$ & 0.080 \\
\hline
\end{tabular}

Notes

-All variables are in natural logs.

-ADF is the Augmented Dickey-Fuller test, PP is the Phillips Perron test and KPSS the Kwiatkowski-Phillips-Schmidt-Shin test.

- The model contains a constant and a deterministic trend.

$-*, * *$ and $* * *$ denote statistical significance at the $1 \%, 5 \%$ and $10 \%$ level respectively

All tests indicate that the series are nonstationary in levels while in first differences form turns stationary. Having established that the examined series are integrated of order one, $I(1)$, we proceed with testing for possible cointegration using the ARDL methodology as described above.

The corresponding equations of the ARDL model are presented below:

$$
\begin{aligned}
& \Delta l s p_{t}=a_{0}+\sum_{i=1}^{p} a_{1 i} \Delta l s p_{t-i}+\sum_{i=0}^{q} \alpha_{2 i} \Delta \text { lReer }_{t-i}+\sum_{i=0}^{Z} \alpha_{2 i} \Delta l w t i_{t-i}+\theta_{1} l s p_{t-1}+\theta_{2} \text { lreer }_{t-1} \\
& +\theta_{3} l w t i_{t-1}+u_{t} \\
& \text { sreer }_{t}=a_{0}+\sum_{i=1}^{p} a_{1 i} \text { ulreer }_{t-i}+\sum_{i=0}^{q} \alpha_{2 i} \Delta l s p_{t-i}+\sum_{i=0}^{Z} \alpha_{2 i} \Delta \text { lwti } i_{t-i}+\theta_{1} \text { lreer }_{t-1}+ \\
& \theta_{2} l s p_{t-1}+\theta_{3} l w t i_{t-1}+u_{t} \\
& \Delta l w t i_{t}=a_{o}+\sum_{i=1}^{p} \beta_{1 i} \Delta l w t i_{t-i}+\sum_{i=0}^{q} \beta_{2 i} \Delta l c p i_{t-i}+\sum_{i=0}^{Z} \alpha_{2 i} \Delta \text { lreer }_{t-i}+\theta_{1} l w t i_{t-1}+\theta_{2} l c p i_{t-1} \\
& +\theta_{3} \text { lreer }_{t-1}+u_{t}
\end{aligned}
$$


The results of the bounds test for cointegration are presented below in Table 2. The test provides evidence in favor of non-rejection of the null hypothesis of no long-run causal effect from LREER and LRWTI to LRMSP (the computed $F$ statistic equals 2.38 , which is smaller than the $95 \%$ upper bound critical value) with $\Delta l r m s p$ as the dependent variable following equation (7). In contrast, the computed $\mathrm{F}$ statistic of equation (8) implies that the null hypothesis is rejected ( $F$ statistic equals 6.97 , which is higher than the 95\% upper bound critical value) therefore there is a cointegration relationship among the examined variables running from LRMSP and LRWTI to LREER. On the other hand the results of the Bound F-statistic for equation (9) are not clear at 5\% significance level ( $F$ statistic equals 4.40 , which is between the $95 \%$ lower bound critical value and the $95 \%$ upper bound critical value).

Table 2: Bounds Tests for cointegration

\begin{tabular}{ccccccc}
\hline $\begin{array}{c}\text { Dependent } \\
\text { variable }\end{array}$ & $\begin{array}{c}\text { ARDL model } \\
\text { specification }\end{array}$ & F-Statistic & $\begin{array}{c}95 \% \text { lower } \\
\text { bound }\end{array}$ & $\begin{array}{c}95 \% \text { upper } \\
\text { bound }\end{array}$ & $\begin{array}{c}90 \% \text { lower } \\
\text { bound }\end{array}$ & $\begin{array}{c}90 \% \text { upper } \\
\text { bound }\end{array}$ \\
\hline Ilrmsp & $(2,1,1)$ & 2.38 & & & & \\
$\Delta l$ lreer & $(1,2,4)$ & 6.97 & 3.78 & 4.85 & 3.17 & \\
$\Delta l$ lrwti & $(4,2,3)$ & 4.40 & & & \\
\hline
\end{tabular}

Note: The ARDL specifications were selected based on the Akaike Information Criterion. The maximum lag was set to 4.

It is commonly accepted that the existence of possible significant break points over the examined period could distort the results concerning the cointegration inference. To avoid that possibility, we apply the Bai-Perron (2003) tests of L+1 vs L sequentially determined breaks to endogenously detect the presence of statistically significant structural changes. The results are reported below in Tables 3 to 5 for each of the equations employed.

Table 3: Multiple Breakpoint tests

\begin{tabular}{|c|c|c|c|}
\hline \multicolumn{4}{|c|}{ BAI PERRON TESTS: L+1 VS L Sequential F-statistic determined breaks: } \\
\hline \multicolumn{4}{|c|}{$\operatorname{Lrmsp}_{t}=\beta^{+}{ }_{\text {Lreer }}^{+}+\beta^{-}{ }_{\text {Lreer }}^{-}+\beta^{+}{ }_{\text {Lrwti }}^{+}+\beta_{t}^{-}{ }_{\text {Lrwti }}^{-}+\boldsymbol{U}_{t}(10)$} \\
\hline Break Test & F-statistic & Scaled F-statistic & Critical Value \\
\hline 0 vs. 1 & 19.96 & $99.83 *$ & 18.23 \\
\hline 1 vs. 2 & 14.44 & $72.23 *$ & 19.91 \\
\hline 2 vs. 3 & 2.99 & 14.96 & 20.99 \\
\hline Brake Dates 200 & 8Q3 & & \\
\hline
\end{tabular}

The results reported in table 3, imply that there are two significant brakes detected in the corresponding equation identified on the first quarter of 2001 and the third quarter of 2008. 
Table 4: Multiple Breakpoint tests

BAI PERRON TESTS: L+1 VS L Sequential F-statistic determined breaks:

\begin{tabular}{cccc} 
Lreer $_{\boldsymbol{t}}=\boldsymbol{\beta}^{+}{ }_{\text {rrmsp }_{\boldsymbol{t}}^{+}}^{+}+\boldsymbol{\beta}^{-}{ }_{\text {Lrmsp }_{\boldsymbol{t}}}^{-}+\boldsymbol{\beta}^{+}{ }_{\text {Lrwti }}{ }_{\boldsymbol{t}}^{+}+\boldsymbol{\beta}^{-}{ }_{\text {Lrwti }}{ }_{\boldsymbol{t}}+\boldsymbol{U}_{\boldsymbol{t}}(\mathbf{1 1})$ \\
\hline Break Test & F-statistic & Scaled F-statistic & Critical Value \\
0 vs. 1 & 100.19 & $500.99^{*}$ & 18.23 \\
1 vs. 2 & 14.46 & $72.33^{*}$ & 19.91 \\
2 vs. 3 & 8.32 & $41.60^{*}$ & 20.99 \\
3 vs. 4 & 4.69 & $23.49^{*}$ & 21.71 \\
4 vs. 5 & 1.20 & 6.04 & 22.37
\end{tabular}

Brake Dates 1995Q2, 2000Q4, 2005Q4, 2011Q3

* Significant at the 0.05 level. Maximum breaks 5

-Bai-Perron (Econometric Journal, 2003) critical values.

The Bai-Perron test implies the existence of 4 break points in equation (11) identified on the second quarter of 1995, the fourth quarter of 2000, the fourth quarter of 2005 and the third quarter of 2011.

Table 5: Multiple Breakpoint tests

BAI PERRON TESTS: L+1 VS L Sequential F-statistic determined breaks:

$$
{ }_{L W T I} t=\beta^{+}{ }_{L R E E R}^{+}+\beta^{-}{ }_{L R E E R}^{-}+\beta^{+}{ }_{L M S P_{t}^{+}}^{+}+\beta^{-}{ }_{L M S P_{t}^{-}}+u_{t}(12)
$$

\begin{tabular}{lccc}
\hline \multicolumn{1}{c}{ Break Test } & F-statistic & Scaled F-statistic & Critical Value \\
0 vs. 1 & 64.18 & $320.93^{*}$ & 18.23 \\
1 vs. 2 & 4.78 & $23.91^{*}$ & 19.91 \\
2 vs. 3 & 3.75 & 18.76 & 20.99 \\
Brake Dates $1992 \mathrm{Q} 1 \& 2000 \mathrm{Q} 1$ & &
\end{tabular}

* Significant at the 0.05 level. Maximum breaks 5

-Bai-Perron (Econometric Journal, 2003) critical values.

In equation (12) the results reveal the presence of 2 brakes in the following bates, first quarter of 1992 and 2000. After identifying the brakes in each equation, we constructed both impulse and stability dummies following the proposed breakpoint identification in order to incorporate the effect of structural changes in the examined relationship. Then, we proceed by employing the NARDL approach, including in the equations the structural brakes we identified. The results of the bounds test for cointegration are presented below in Table 6.

Table 6: Bounds Tests for Cointegration

\begin{tabular}{ccccccc}
\hline Model & $\begin{array}{c}\text { Dependent } \\
\text { Variable }\end{array}$ & FPSS-Nonlinear & $\begin{array}{c}95 \% \text { Lower } \\
\text { bound }\end{array}$ & $\begin{array}{c}95 \% \text { Uper } \\
\text { bound }\end{array}$ & $\begin{array}{c}90 \% \text { Lower } \\
\text { bound }\end{array}$ & $\begin{array}{c}95 \% \text { Uper } \\
\text { bound }\end{array}$ \\
\hline 1 & $\Delta$ Lrmsp & 5.70 & & & & \\
2 & $\Delta$ Lreer & 5.18 & 2.86 & 4.01 & 2.45 & 3.52 \\
3 & $\Delta$ Lrwti & 8.39 & & & & \\
\hline
\end{tabular}

Note: The ARDL specifications were selected based on the Akaike Information Criterion. The maximum lag was set to 5. FPSS-Nonlinear denote the PSS F-statistic testing the null hypothesis $\rho=\theta+=\theta-=0$ respectively. Model 1 includes two stability dummies on 2001 first quarter, 2008 third quarter. Model 2 includes two impulse dummies on 1995 and 2011 first quarter, and Model 3 includes two stability dummies on 1992 and 2000 first quarter. 
The F-statistic for the joint significance of the parameters of the lagged level variables is exceeds the $95 \%$ upper bound critical value and reveals statistically significant evidence in favor of the existence of a long-run cointegrating relationship between the examined variables in all models. The dynamic estimation of series adjustments can be reproduced via an error-correction model (ECM). When the asymmetries in the short- and long-run dynamics are introduced into the standard ECM, we obtain a more general cointegration model (Shin et al, 2011) as follows:

$$
\begin{aligned}
& \Delta \text { lrmsp }_{t}=\text { cons }+ \text { olrmsp }_{t-1}+\theta_{i}^{+} \text {lreer }_{t-l}^{+}+\theta_{i}^{-} \text {lreer }_{t-l}^{-}+\theta_{i}^{+} \text {lrwti }_{t-l}^{+}+\theta_{i}^{-} l r w t i_{t-l}^{-}+ \\
& \sum_{i=1}^{c-1} \theta_{i} \text { lrmsp }_{t-i}+\sum_{i=0}^{d} \pi_{i}^{+} \Delta_{\text {lreer }}^{+}+\sum_{t=0}^{d} \pi_{i}^{-} \Delta \text { lreer }_{t-i}^{-}+\sum_{i=0}^{d} \pi_{i}^{+} \Delta \text { lrwti }_{t-i}^{+}+\sum_{i=0}^{d} \pi_{i}^{-} \Delta l r w t i_{t-i}^{-}+e_{t} \\
& \Delta \text { lreer }_{t}=\text { cons }+ \text { olreerp }_{t-1}+\theta_{i}^{+} \text {lrmsp }_{t-1}^{+}+\theta_{i}^{-} \text {lrmsp }_{t-1}^{-}+\theta_{i}^{+} \text {lrwti }_{t-1}^{+}+\theta_{i}^{-} l r w t i_{t-1}^{-}+ \\
& \sum_{i=1}^{c-1} \theta_{i} \text { lreer }_{t-i}+\sum_{i=0}^{d} \pi_{i}^{+} \Delta \text { lrmsp }_{t-i}^{+}+\sum_{i=0}^{d} \pi_{i}^{-} \Delta \text { lrmsp }_{t-i}^{-}+\sum_{i=0}^{d} \pi_{i}^{+} \Delta l r w t i_{t-i}^{+}+\sum_{i=0}^{d} \pi_{i}^{-} \Delta r w t i_{t-i}^{-}+e_{t} \\
& \Delta l r w t i_{t}=\text { cons }+ \text { olrwti } i_{t-1}+\theta_{i}^{+} \text {lrmsp }_{t-1}^{+}+\theta_{i}^{-} \text {lrmsp }_{t-1}^{-}+\theta_{i}^{+} \text {lreer }_{t-1}^{+}+\theta_{i}^{-} \text {lreer }_{t-1}^{-}+
\end{aligned}
$$

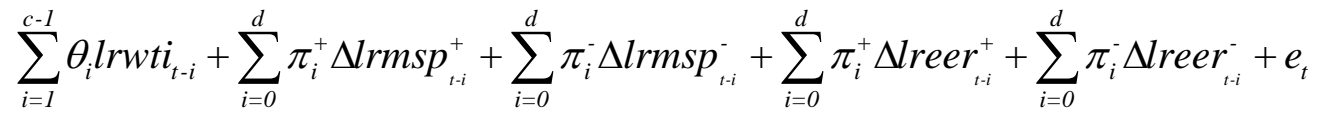

In order to select the final ARDL specification for each case, we follow the general-to-specific approach.

\begin{tabular}{|c|c|c|c|c|}
\hline \multicolumn{5}{|c|}{ Dependent Variable $\Delta$ Lrmsp } \\
\hline Variable & Coefficient & Std. Error & t-Statistic & Prob. \\
\hline $\operatorname{Lrmsp}(-1)$ & -0.285 & 0.055 & -5.166 & 0.000 \\
\hline $\operatorname{Lrwti}^{+}(-1)$ & 0.016 & 0.035 & 0.473 & 0.637 \\
\hline $\operatorname{Lrwti}^{-}(-1)$ & 0.120 & 0.049 & 2.438 & 0.016 \\
\hline $\operatorname{Lreer}^{+}(-1)$ & 0.967 & 0.272 & 3.544 & 0.000 \\
\hline $\operatorname{Lreer}^{-}(-1)$ & -0.286 & 0.173 & -1.647 & 0.102 \\
\hline$\Delta \operatorname{Lrmsp}(-1)$ & 0.269 & 0.088 & 3.035 & 0.003 \\
\hline$\Delta \operatorname{Lrwti}^{+}(-1)$ & -0.143 & 0.070 & -2.031 & 0.044 \\
\hline$\Delta$ Lrwti $^{-}$ & 0.193 & 0.055 & 3.499 & 0.000 \\
\hline$\Delta$ reer $^{-}(-1)$ & -0.694 & 0.381 & -1.820 & 0.071 \\
\hline $\mathrm{C}$ & 0.852 & 0.168 & 5.062 & 0.000 \\
\hline D 2001Q1 & -0.107 & 0.032 & -3.318 & 0.001 \\
\hline D2008Q3 & -0.162 & 0.036 & -4.487 & 0.000 \\
\hline $\mathrm{R}^{2}$ & 0.407 & & & \\
\hline Adjusted $\mathrm{R}^{2}$ & 0.347 & & & \\
\hline $\mathrm{L}($ lrwti)+ & 0.056 & & & 0.766 \\
\hline L(lrwti)- & 0.421 & & & 0.001 \\
\hline L(lreer)+ & 3.392 & & & 0.000 \\
\hline L(lreer)- & -1.002 & & & 0.319 \\
\hline $\mathrm{W}_{\mathrm{LR}}($ lrwti) & $3.63 * *$ & & & $18.25^{*}$ \\
\hline $\mathrm{W}_{\mathrm{SR}}($ lrwti) & $11.79 *$ & & & - \\
\hline
\end{tabular}
The preferred specification, is chosen by starting with $\max p$ and $\max q=4$ and dropping all insignificant stationary regressors. The results of the Asymmetric ECM of the form of the equations of 13 to 15 are presented in Tables 7, 8 and 9 correspondingly.

Table 7: Asymmetric Error Correction Model

Notes:*,** and $* * *$ denote statistical significance at the $1 \%, 5 \%$ and $10 \%$ level respectively. 
- D 2001Q1, D2008Q3 are stability dummies

- $L^{+}{ }_{l w t i}$ is the estimated long-run coefficient associated with positive changes, defined by $\beta^{+}=-\theta^{+} / \rho$.

- $L_{l w t i}^{-}$is the estimated long-run coefficient associated with negative changes, defined by $\beta^{-}=-\theta^{-} / \rho$.

- $W_{L R}$ refers to the Wald test for the null of long-run symmetry defined by $-\theta^{+} / \rho=-\theta^{-} / \rho$.

- $W_{S R}$ refers to the Wald test for the null of the additive short-run symmetry condition defined by $\sum_{\mathrm{i}=0}^{\mathrm{q}} \pi_{i}^{+}=\sum_{\mathrm{i}=0}^{\mathrm{q}} \pi_{i}^{-}$.

In order to verify existence of asymmetry, we applied the Wald tests for both long- $\left(\mathrm{W}_{\mathrm{LR}}\right)$ and short-run $\left(\mathrm{W}_{\mathrm{SR}}\right)$ symmetry. The results of equation (13), table 7, imply the existence of long-run and short-run asymmetry. In particular, in the long-run horizon the Wald tests suggest the rejection of the null hypothesis of long-run symmetry between the positive and negative components of each one of the examined variables. Regarding the effects to stock prices only the negative oil price changes ( $\left(\right.$ (lrwti) ${ }^{-}=$ $0.421)$ and positive exchange rate shocks $\left(\mathrm{L}(\mathrm{lreer})^{+}=3.392\right)$ have a significant effect with a positive sign. In the sort-run we also detect the existence of asymmetric response of oil price shocks to stock prices $\left(\mathrm{W}_{\mathrm{SR}}=11.79\right)$ and both positive and negative components are statistically significant.

Table 8: Asymmetric Error Correction Model

\begin{tabular}{|c|c|c|c|c|}
\hline \multicolumn{5}{|c|}{ Dependent Variable $\Delta$ LREER } \\
\hline Variable & Coefficient & Std. Error & t-Statistic & Prob. \\
\hline LREER(-1) & -0.125 & 0.029 & -4.270 & 0.000 \\
\hline $\operatorname{Lrmsp}^{+}(-1)$ & 0.046 & 0.019 & 2.302 & 0.023 \\
\hline $\operatorname{Lrmsp}^{-}(-1)$ & 0.026 & 0.018 & 1.419 & 0.158 \\
\hline Lrwti+ $(-1)$ & -0.029 & 0.012 & -2.400 & 0.018 \\
\hline Lrwti-(-1) & -0.017 & 0.008 & -2.155 & 0.033 \\
\hline$\Delta \mathrm{Lrmsp}^{+}$ & -0.121 & 0.065 & -1.841 & 0.068 \\
\hline$\Delta \operatorname{Lrmsp}+(-1)$ & 0.123 & 0.063 & 1.950 & 0.053 \\
\hline$\Delta$ Lrwti+ & -0.014 & 0.051 & -0.274 & 0.784 \\
\hline$\Delta$ Lrwti- & -0.063 & 0.027 & -2.348 & 0.020 \\
\hline $\mathrm{C}$ & -0.109 & 0.023 & -4.599 & 0.000 \\
\hline D1995Q2 & 0.573 & 0.137 & 4.177 & 0.000 \\
\hline D2011Q2 & -0.045 & 0.020 & -2.234 & 0.027 \\
\hline $\mathrm{R}^{2}$ & 0.488 & & & \\
\hline Adjusted $\mathrm{R}^{2}$ & 0.431 & & & \\
\hline $\mathrm{L}($ lrmsp $)+$ & 0.386 & & & 0.017 \\
\hline L(lrmsp)- & 0.208 & & & 0.152 \\
\hline $\mathrm{L}($ lrwti)+ & -0.236 & & & 0.012 \\
\hline L(lrwti)- & -0.139 & & & 0.030 \\
\hline $\mathrm{W}_{\mathrm{LR}}(\mathrm{msp})$ & 0.360 & & & 0.687 \\
\hline $\mathrm{W}_{\mathrm{SR}}(\mathrm{msp})$ & - & & & 0.869 \\
\hline
\end{tabular}

Notes:*, ** and *** denote statistical significance at the $1 \%, 5 \%$ and $10 \%$ level respectively.

- D1995Q2 and D2011Q3 are impulse dummies

- $L^{+}{ }_{\text {lwti }}$ is the estimated long-run coefficient associated with positive changes, defined by $\beta^{+}=-\theta^{+} / \rho$.

- $L_{l w t i}^{-}$is the estimated long-run coefficient associated with negative changes, defined by $\beta^{-}=-\theta^{-} / \rho$.

- $W_{L R}$ refers to the Wald test for the null of long-run symmetry defined by $-\theta^{+} / \rho=-\theta^{-} / \rho$.

- $W_{S R}$ refers to the Wald test for the null of the additive short-run symmetry condition defined by $\sum_{\mathrm{i}=0}^{\mathrm{q}} \pi_{i}^{+}=\sum_{\mathrm{i}=0}^{\mathrm{q}} \pi_{i}^{-}$.

The asymmetric ECM of the equation (14) is presented in Table 8. The Wald test for long-run $\left(\mathrm{W}_{\mathrm{LR}}\right)$ symmetry suggests the non-rejection of the null hypothesis of long-run symmetry between the positive and negative components of stock and oil price changes. Although, the coefficients of the estimated long-run components of stock prices imply that only the positive changes are significant $\left(\mathrm{L}(\mathrm{lrmsp})^{+}=0.386\right)$. Therefore, we may conclude that there is an asymmetric impact of stock price changes to exchange rates in the long-run. 
Table 9: Asymmetric Error Correction Model

\begin{tabular}{|c|c|c|c|c|}
\hline \multicolumn{5}{|c|}{ Dependent Variable $\Delta$ Lrwti } \\
\hline Variable & Coefficient & Std. Error & t-Statistic & Prob. \\
\hline Lrwti(-1) & -0.451 & 0.073 & -6.118 & 0.000 \\
\hline Lrmsp+(-1) & 0.539 & 0.153 & 3.522 & 0.000 \\
\hline Lrmsp- $(-1)$ & 0.293 & 0.110 & 2.655 & 0.009 \\
\hline Lreer $+(-1)$ & -2.072 & 0.480 & -4.314 & 0.000 \\
\hline Lreer- $(-1)$ & -1.219 & 0.361 & -3.378 & 0.001 \\
\hline$\Delta$ Lreer+ & -4.718 & 0.681 & -6.926 & 0.000 \\
\hline$\Delta$ Lreer+ $(-1)$ & -1.500 & 0.637 & -2.354 & 0.020 \\
\hline$\Delta$ Lreer- & -2.273 & 0.792 & -2.868 & 0.005 \\
\hline$\Delta$ Lreer- $(-2)$ & -1.549 & 0.708 & -2.186 & 0.031 \\
\hline C & 1.278 & 0.218 & 5.849 & 0.000 \\
\hline D1992Q1 & -0.204 & 0.060 & -3.353 & 0.001 \\
\hline D2000Q1 & 0.276 & 0.073 & 3.768 & 0.000 \\
\hline $\mathrm{R}^{2}$ & 0.550 & Adjusted $\mathrm{R}^{2}$ & & 0.504 \\
\hline L(Irmsp)+ & 1.196 & & & 0.000 \\
\hline L(Irmsp)- & 0.650 & & & 0.008 \\
\hline L(Ireer)+ & -4.592 & & & 0.000 \\
\hline L(Ireer)- & -2.703 & & & 0.000 \\
\hline $\mathrm{W}_{\mathrm{LR}}(\mathrm{msp})$ & 0.545 & & $\mathrm{~W}_{\mathrm{LR}}$ (reer) & $-2.833^{\star *}$ \\
\hline $\mathrm{W}_{\mathrm{SR}}(\mathrm{msp})$ & - & & $\mathrm{W}_{\mathrm{SR}}$ (reer) & 2.533 \\
\hline
\end{tabular}

Notes:*,** and *** denote statistical significance at the $1 \%, 5 \%$ and $10 \%$ level respectively.

- D 1992Q1, D2000Q1 are stability dummies

- $L^{+}{ }_{l w t i}$ is the estimated long-run coefficient associated with positive changes, defined by $\beta^{+}=-\theta^{+} / \rho$.

- $L^{-}{ }_{\text {lwti }}$ is the estimated long-run coefficient associated with negative changes, defined by $\beta^{-}=-\theta^{-} / \rho$.

- $W_{L R}$ refers to the Wald test for the null of long-run symmetry defined by $-\theta^{+} / \rho=-\theta^{-} / \rho$.

- $W_{S R}$ refers to the Wald test for the null of the additive short-run symmetry condition defined by $\sum_{\mathrm{i}=0}^{\mathrm{q}} \pi_{i}^{+}=\sum_{\mathrm{i}=0}^{\mathrm{q}} \pi_{i}^{-}$.

Regarding the long-run dynamics, of the equation (15) the results imply the existence of an asymmetric impact running from exchange rate changes to oil prices. The long-run coefficients of the asymmetric ECM and Llreer ${ }^{+}$and Llreer were found significant, -4.592 and -2.703 , and negative. Therefore, we may conclude that a $1 \%$ increase in exchange rates results in a $4.59 \%$ decrease in oil prices. Similarly, a $1 \%$ decrease in the exchange rates leads to a $2.70 \%$ increase in oil prices. Hence, our results indicate that the greater effect is sourcing from the positive changes.

\section{Summary and Conclusions}

We investigated the dynamic linkages between US Stock prices, exchange rates and oil prices using quarterly data for the period 1986 to 2016. We employed the ARDL approach and we detected the existence of one cointegration relationship running from stock prices and oil prices to exchange rates. By using the non-linear cointegration methodology, the asymmetric Autoregressive Distributed Lag cointegration technique, including also the brakes from the regression of the dependent variable to the decomposed parameters of the explanatory variables, which were endogenously detected by the use of the Bai-Perron test, we reexamine the relationship among the variables. The NARDL methodology permits the exploration of possible asymmetric effects in both the long- and short-run time horizon. The results of NARDL approach reveals the existence of cointegration relationship in all models examined.

In the long-run horizon the results imply that stock prices are asymmetrically affected by both exchange rates and oil price shocks. The relationship between exchange rates and stock prices and oil prices and stock prices is positive. The impact of the negative changes of oil prices and the positive of exchange 
rates on stock prices is higher than the other components correspondingly. In the sort-run horizon we also have detected the presence of asymmetry as the impact of negative oil prices is higher. The positive relationship between oil prices and stock prices can be explained by the fact that oil prices can be driven by demand side shocks, while the positive relationship between exchange rates and stock prices can be attributed to several reasons as described by the theory.

Turning our analysis to the impacts on exchange rates, we found that there is a cointegration relationship running from stock prices and oil prices to exchange rates. In addition, we detected the presence of asymmetric long-run effects; only the positive components of stock prices affect exchange rates.

Finally, we also found a cointegration relationship running from stock prices and exchange rates to oil prices. The results reveal a positive long-run equilibrium relationship between stock prices and oil prices and a negative one between exchange rates and oil prices. Regarding the long-run coefficients we found that positive exchange rates have a greater impact on oil prices $\left(\mathrm{L}(\mathrm{lreer})^{+}=-4.592\right)$ than negative exchange rates changes $\left(\mathrm{L}(\mathrm{lreer})^{-}=-2.703\right)$ implying the presence of asymmetry in the effects of the exchange rates on oil price changes. The negative long-run relationship between exchange rates and oil prices can be explained by the theory; U.S. dollar depreciation decreases oil prices for consumers in other countries, thereby increasing their crude oil demand. On the other hand oil-exporting countries would try to stabilize the purchasing power of their export revenues in U.S. dollar raising oil prices. Also, we detected a positive long-run relationship between stock prices and oil prices. Those results can be explained from the fact that strong economic performance can affect the oil prices too through the increase in oil demand.

\section{References}

Aggarwal, R. (1981) Exchange rates and stock prices: a study of the US capital markets under floating exchange rates, Akron Business and Economic Review Fall, 7-12

Alsalman, Z., and Herrera, A.M. (2015) Oil Price Shocks and the U.S. Stock Market: Do Sign and Size Matter?, The Energy Journal, 36(3), 171-188.

Antonakakis, N., Gupta, R., Kollias, C., \& Papadamou, S. (2017). Geopolitical risks and the oil-stock nexus over 1899-2016. Finance Research Letters, 23, 165-173.

Apergis, N., and Miller, S.M. (2009) Do structural oil -market shocks affect stock prices?, Energy Economics, 31(4), 569-575.

Arouri, M. E. H., and Rault, C. (2012) Oil prices and stock markets in GCC countries: Empirical evidence from panel analysis, International Journal of Finance \&Economics, 17, 242-253.

Bai, J. and Perron, P. (1998) Estimating and Testing Linear Models with Multiple Structural Changes, Econometrica, 66(1): 47-78.

Bai, J. and Perron, P. (2003) Computation and analysis of multiple structural change models, Journal of Applied Econometrics, 18, 1-22.

Bai, S. and Koong, K.S. (2018) Oil prices, stock returns, and exchange rates: Empirical evidence from China and the United States, North American Journal of Economics and Finance, 44, 12-33.

Basher, S., Haug, A., and Sadorsky, P. (2012) Oil prices, exchange rates and emerging stock markets, Energy Economics, 34 (1), 227-240.

Basher, S.A., and Sadorsky, P. (2006) Oil price risk and emerging stock markets, Global Finance Journal, 17, 224-251.

Bénassy-Quéré, A., Mignon, V., and A. Penot. (2007) China and the relationship between the oil price and the Dollar, Energy Policy, 35, 5795-5805.

Branson, W.H. (1983) Macroeconomic Determinants of Real Exchange Risk, In Managing Foreign Exchange Risk, Ed. R. J. Herring, Cambridge University Press, Cambridge.

Chen, S.S., and Chen, H.C. (2007) Oil prices and real exchange rates, Energy Economics, 29(3), 390-404.

Chen, Y., Rogoff, K., and Rossi, B. (2010) Can exchange rates forecast commodity prices?, Quarterly Journal of Economics, 125, 1145-1194. 
Chow, E.H., Lee, W.Y., and Solt, M.S. (1997) The exchange rate risk exposure of asset returns, Journal of Business, 70, 105-123.

Coudert, V., Couharde, C., and Mignon, V. (2008) Do terms of Trade Drive Real Exchange Rates? Comparing Oil and Commodity Currencies, CEPII Working Paper, 32, December.

Cox, J.C., J.E. Ingersoll, and S.A. Ross. (1985) A Theory of the Term Structure of Interest Rates, Econometrica, 53, 385-407.

Delgado, N.A.B., Delgado, E.B., and Saucedo, E. (2018) The relationship between oil prices, the stock market and the exchange rate: Evidence from Mexico, The North American Journal of Economics and Finance, 45, 266-275.

Dickey, D.A., and Fuller, W.A. (1979) Distribution of the Estimators for Autoregressive Time- Series with a Unit Root, Journal of American Statistical Association, 74, 427-431.

Dornbusch, R., S. Fisher. (1980) Exchange rates and the current account, American Economic Review, 70, 960-971.

Frankel, J.A. (1983) Monetary and Portfolio-Balance Models of Exchange Rate Determination, Economic Interdependence and Flexible Exchange Rates, J. S. Bhandari and B. H. Putnam eds., Cambridge: MIT Press.

Gavin, M. (1989) The stock market and exchange rate dynamics, Journal of International Money and Finance 8, 181-200.

Ghosh, S., and Kanjilal, K. (2016) Co-movement of international crude oil price and Indian stock market: evidences from nonlinear cointegration tests, Energy Economics, 53,111-117.

Golub, S. (1983) Oil prices and exchange rates, Economic Journal, 93, 576-593.

Groen, J.J.J., and, Pesenti, P.A. (2011) Commodity prices, commodity currencies, and global economic developments. In T. Ito, and A. Rose (Eds.), Commodity prices and markets, East Asia Seminar on Economics, 20, 15-42. Chicago: University of Chicago Press.

Huang, R., R., Masulis, and H.Stoll. (1996) Energy Shocks and Financial Markets, Journal of Futures Markets, 16, 1-27.

Jain, A., and Biswal, P.C. (2016) Dynamic linkages among oil price, gold price, exchange rate, and stock market in India, Resources Policy, 49, 179-185.

Jones, C.M., and Kaul, G. (1996) Oil and the stock markets, Journal of Finance, 55, 463-491.

Joseph, N. (2002) Modelling the impacts of interest rate and exchange rate changes on UK stock returns, Derivatives Use, Trading \& Regulation, 7, 306-323.

Kilian, L., and Park, C. (2009) The impact of oil price shocks on the U.S. stock market, International Economic Review, 50, 1267-1287.

Kollias, C., Kyrtsou, C., \& Papadamou, S. (2013). The effects of terrorism and war on the oil price-stock index relationship. Energy Economics, 40, 743-752.

Kollias, C., Mylonidis, N., \& Paleologou, S. M. (2012). The nexus between exchange rates and stock markets: evidence from the euro-dollar rate and composite European stock indices using rolling analysis. Journal of Economics and Finance, 36(1), 136-147.

Kollias, C., Papadamou, S., \& Siriopoulos, C. (2016). Stock markets and effective exchange rates in European countries: threshold cointegration findings. Eurasian Economic Review, 6(2), 215-274.

Krichene, N. (2005) A simultaneous equations model for world crude oil and natural gas markets, IMF Working Paper Series.

Krugman, Paul. (1983b) Oil shocks and exchange rate dynamics, Exchange Rates and International Macroeconomics, edited by J. A. Frankel. Chicago: University of Chicago Press.

Kwiatkowski, D., Phillips, P.C.B., Schmidt, P., and Shin, Y. (1992) Testing the null hypothesis of stationarity against the alternative of a unit root: How sure are we that economic time series have a unit root?, Journal of Econometrics, 54, 159-178.

Lee, C.C., and J.H. Zeng. (2011) Revisiting the Relationship between Spot and Futures Oil Prices: Evidence from Quantile Cointegrating Regression, Energy Economics, 33, 924-935.

Lizardo, R.A., and Mollick, A.V. (2010) Oil price fluctuations and US dollar exchange rates, Energy Economics, 32, 399-408. 
Merton, R.C. (1973) Theory of Rational Option Pricing. The Bell Journal of Economics and Management Science, 4(1), 141-183.

Mishra, K.A. (2004) Stock Market and Foreign Exchange market in India: Are they related?, South Asia Economic Journal, 5(2), 209-232.

Mohanty, S., Nandha, M., and Bota, G. (2010) Oil shocks and stock returns: The case of the Central and Eastern European (CEE) oil and gas sectors, Emerging Markets Review, 11(4), 358-372.

Moya-Martínez, P., Ferrer-Lapeña, R., and Escribano-Sotos, F. (2014) Oil price risk in the Spanish stock market: an industry perspective, Economic Modelling, 37, 280-90.

Narayan, P., Sharma, S. (2011) New evidence on oil price and firm returns, Journal of Banking and Finance, 35, 3253-3262.

Narayan, P.K., and Gupta, R. (2015) Has oil price predicted stock returns for over a century?, Energy Economics, 48, 18-23.

Narayan, P.K., Narayan, S. (2010) Modelling the impact of oil prices on Vietnam's stock prices, Applied Energy, 87, 356-361.

Park, J. and R.A. Ratti. (2008) Oil Price Shocks and Stock Markets in the U.S. and 13 European Countries, Energy Economics, 30, 2587-2608.

Pesaran, M.H., and Shin, Y. (1999) An autoregressive distributed lag modeling approach to cointegration analysis, In S. Strøm (Ed.), Econometrics and economic theory in the 20th Century: The Ragnar Frisch Centennial Symposium. Cambridge: Cambridge University Press.

Pesaran, M.H., Shin, Y., and Smith, R.J. (2001) Bounds testing approaches to the analysis of level relationships, Journal of Applied Econometrics, 16, 289-326.

Phillips, P.C.B., and Perron, P. (1988) Testing for a Unit Root in Time Series Regression, Bio-metrica, 75, 335-346.

Phylaktis, K. \& Ravazzolo, F. (2005) Stock prices and exchange rate dynamics, Journal of International Money and Finance, 24, 1031-1053.

Roll, R. (1992) Industrial structure and the comparative behavior of international stock markets indices, Journal of Finance, 47, 3-41.

Ross, S. (1976) The Arbitrage Theory of Capital Asset Pricing, Journal of Finance, 13, 341-360.

Roubaud, D., and Arouri, M. (2018) Oil prices, exchange rates and stock markets under uncertainty and regime-switching, Finance Research Letters in press.

Sadorsky, P. (1999) Oil Price Shocks and Stock Market Activity, Energy Economics, 21, 449-469.

Salisu, A.A. and Isah, K.O. (2017) Revisiting the oil price and stock market nexus: A nonlinear Panel ARDL approach, Economic Modelling, 66, 258-271.

Schorderet, Y. (2003) Asymmetric Cointegration. Working Paper No 2003.01, Department of Econometrics, University of Geneva, Geneva

Shin, Y., Yu, B., and Greenwood-Nimmo, M. (2011) Modelling asymmetric cointegration and dynamic multipliers in a nonlinear ARDL framework. Mimeo.

Soenen, L.A., and Hennigar, E.S. (1988) An analysis of exchange rates and stock prices the US experience between 1980 and 1986, Akron Business and Economic Review Winter, 7-16.

Xiao, J.H., Zhou, M., Wen, F.M., and Wen, F.H. (2018) Asymmetric impacts of oil price uncertainty on Chinese stock returns under different market conditions: evidence from oil volatility index,Energy Economics, 74, 777-786.

Zhang,Y-F., Fan,Y., Tsai,H-T. and Wei,Y-M. (2008) Spillover effect of US dollar exchange rate on oil prices, Journal of Policy Modelling, 30, 973-991. 